\title{
THE INFLUENCE OF ACIDIC BUFFER AND MECHANICAL BRUSHING ON THE WEIGHT LOSS AND SURFACE ROUGHNESS OF THREE DIFFERENT CAD-CAM MATERIALS
}

\author{
Mohamed Mohey Eldin Mohamed*
}

\begin{abstract}
Aim of the work was to investigate the effect of $\mathrm{pH}$ media and the influence of the mechanical tooth brushing on the weight loss and surface roughness ( $\mathrm{Ra}$ ) of zirconia-reinforced lithium silicate glass ceramic, hybrid ceramic material and composite material.

Materials \& Methods: Three types of dental materials were selected. One Composite resin material (Cerasmart), Lithium silicate glass ceramic with 10\% Zirconia (Celtra Duo) and one hybrid ceramic (Vita Enamic). Eighty one disc shaped specimens $(2 \mathrm{~mm}$ in height and $12 \mathrm{~mm}$ in diameter) were fabricated from three different CAD/CAM materials then divided into three groups of twenty seven specimens each $(n=27)$ based on the treatments received. Group I Twenty seven specimens 9 from each material, recieve no treatment and were weighted examined by optical microscpe for surface topogrphy. Group II, Twenty seven specimens 9 from each material were stored in acidic buffer for 168 hours then weighted. Group III, Twenty seven specimens 9 from each material were subjected to mechanical brushining and examined by optical microscpe (for quantity and quality of surface roughness). The raw data were obtained from different tests and analyzed. $\mathrm{T}$ test and One-way ANOVA were conducted to compare the effect of the acidic buffer storage period and mechanical brushing on the weight loss and surface roughness respectively .
\end{abstract}

Resuts: Comparison between weight loss before and after acidic buffer storage in the three groups using ANOVA analysis test showed that there was no significant difference between the three groups regarding to weight loss (0.05). The weight loss of Cerasmart group was heigher than the other two groups and there was no significant difference in surface roughness among the tested groups following 50,000 brushing cycles. The Vita Enamic materials showed lower surface roughness mean value compared to surface roughness value of Celtra Duo and Cerasmart material .

Conclusions: Within the limitations of the present study, there was no significant difference in both weight loss and surface roughness of tested materials after 168 hours storage in acidic buffer and Simulated 5 years of brushing but Cerasmart composite has the highest weight loss and surface roughness

\footnotetext{
* Lecturer of Fixed Prosthodontics, Delta University For Science and Technology
} 


\section{INTRODUCTION}

Increased demand for tooth-colored restorations has resulted in an increase in the use of all-ceramic materials $^{1}$

All ceramic restorations minimized the drawbacks of porcelain fused to metal and became the first choice for highly aesthetic results. The trend towards all ceramics is becoming more and more popular. These restorations should have smooth external surfaces for periodontal health, and aesthetic outcome .2

Ceramics are inert materials, that have no changes in the oral cavity, on the other hand composite materials suffer moderate degradation as a result of mechanical and chemical interaction in the presence of acidic changes in the oral cavity. ${ }^{3,4}$

The gastro-esophageal reflux disease (GERD) is characterized by collection of gastric acid in the oral cavity for periods of time, lead to degradation of the dentition and restorations. ${ }^{5,6}$

The effect of acids on ceramic surfaces showed that immersion of ceramics in acidic buffer for 168 hours may have drawbacks on the mechanical behavior of ceramics, in addition to alteration of their fracture strength as a result of surface flaws. Tooth brushing has important role in changes of the surface roughness of ceramic restorations that may result in loss of lustre and color staining ${ }^{7,8}$

The longevity of the tooth colored restorations depend on their surface characteristics. Surface roughness and degradation of ceramic restorations by the exposure to acidic enviroment results in releasing of alkaline ions, which are less stable in the glassy phase than in the crystalline phases. ${ }^{9}$

In-vitro surface roughness measurements after mechanical tooth brushing were performed to predict the clinical behavior of the materials and the extent of stain or wear. ${ }^{10}$

Many factors affect the behavior of the ceramic or composite materials after mechanical tooth brushing test some of these factors are crystalline particles size, glassy matrix, filler content, and resin matrix. Other non material factors as brush type, load, dentifrices and number of brushing cycles..$^{11,12}$

Lithium disilicate glass ceramic that contain 10\% zirconia by weight (Celtra Duo) is strong enough to be used as monolithic restoration and is claimed to be stronger than the lithium disilicate glass ceramics after crystallization, however little information is available about its clinical performance and resistance to wear and erosion. ${ }^{13}$

A resin-infiltrated ceramic material Vita Enamic is a hybrid ceramic composed of ceramic interpenetrating network infiltrated by a polymer network that combines the positive character of ceramic materials beside those of the composite materials. ${ }^{14}$ Moreover this material shows better wear resistance than conventional composite resin and better mechanical properties.

Wear of composite restorations caused by both occlusal contact and toothbrush abrasion process may lead to change in the surface character of restorations and increase the accumulation of dental plaque..$^{15}$

The continuous development in composite resin materials introduce a nanohybrid and nanofilled resin composites with inorganic ceramic fillers that completly differ in structure and filler contents. The difference in composition is responsible for the higher flexural strengths ,the mechnical perfomance and resistance to wear but the biomechanical behavior of these resin-based composite materials are not extensively studied. ${ }^{16}$

Little information is available about the influence of the toothbrush, toothpaste, the brushing time and pressure load on the surface texture of these dental materials. ${ }^{17}$

The purpose this study is to investigate the effect of $\mathrm{pH}$ media and the influence of the mechanical 
tooth brushing on the surface roughness of zirconiareinforced lithium silicate glass ceramic, hybrid ceramic material and composite material.

The hypotheses was that no difference in weight loss and surface roughness among the tested materials would be found after exposure to acidic condition or mechnical tooth brushing.

\section{MATERIALS AND METHODS}

\section{Materials}

Three types of dental materials were selected for this study. Nano-filled composite resin material, Lithium silicate glass ceramic with $10 \%$ Zirconia and one hybrid ceramic. Table I

\section{Methods}

Eighty one specimens in the form of disc $(2 \mathrm{~mm}$ in height and $12 \mathrm{~mm}$ in diameter) were fabricated from three different CAD/CAM materials then divided into three groups $(n=27)$ based on the treatments received.

\section{Specimens Fabrication.}

TABLE (1) Materials used and there composition.
Prototype disc shape were designed in Atuodesk 3DS Max program 2016, exported to STL file format and imported in inLab 18 softwear (CEREC Software Dentsply Sirona) then 81 disc 27 from each tested material were milled by CEREC inLab MC X5 milling unit.

Crystallization of the ceramic specimens were accomplished using VITA VACUMAT 6000 M furnace (Vita Zahnfabrick, Bad Säckingen, Germany) following the respective manufacturer's recommendations.

After crystallization, all disc specimens were polished using ascending sequence of abrasiveness of silicon carbide paper discs of 400, 600, 800, 1000,1200 grit. ${ }^{18}$ After polishing, all specimens were stored in normal saline in closed clear jars until used.

\section{Specimens grouping and preparation}

Specimens were divided into three groups of twenty seven specimens each.

\section{Group I,}

A total number of Twenty seven specimens

\begin{tabular}{|c|c|c|}
\hline Materials \& trade name & Materials composition & Manufactures \\
\hline Cerasmart & $\begin{array}{l}\text { Composite resin material (BisMEPP, UDMA, } \\
\text { DMA) with } 71 \mathrm{wt} \% \text { silica }(20 \mathrm{~nm}) \text {, and } \\
\text { barium glass nanoparticles }(300 \mathrm{~nm})\end{array}$ & $\begin{array}{l}\text { GC Dental Products Europe, Leuven, } \\
\text { Belgium }\end{array}$ \\
\hline $\begin{array}{c}\text { Vita Enamic } \\
\text { (polymer infiltrated ceramic) }\end{array}$ & $\begin{array}{l}58-63 \% \mathrm{SiO} 2 / 20-23 \% \\
\mathrm{~A} 12 \mathrm{O} 3 / 9-11 \% \mathrm{Na} 2 \mathrm{O} / 4-6 \% \\
\mathrm{~K} 2 \mathrm{O} / 0.5-2 \% \mathrm{~B} 2 \mathrm{O} 3 /<1 \% \\
\mathrm{ZrO} 2 /<1 \% \mathrm{CaO} / \mathrm{UDMA} \\
\mathrm{UDMA} \text { (urethane } \\
\text { dimethacrylate) }\end{array}$ & $\begin{array}{l}\text { Vita Zahnfabrick,Bad Säckingen, } \\
\text { Germany) }\end{array}$ \\
\hline Celtra, Duo & $\begin{array}{l}\text { lithium silicate glass ceramic with } 10 \% \\
\text { Zirconia ( } \mathrm{SiO} 2, \mathrm{Li} 2 \mathrm{O}, \mathrm{K} 2 \mathrm{O}, \mathrm{P} 2 \mathrm{O} 5, \mathrm{~A} 12 \mathrm{O} 3 \text {, } \\
\mathrm{ZrO} 2, \mathrm{CeO} 2 \text {, pigments). }\end{array}$ & $\begin{array}{l}\text {-Dentsplysirona. } 38 \text { West Clarke Avenue } \\
\text { Milford, DE } 19963 \text { USA }\end{array}$ \\
\hline
\end{tabular}


were prepered. Nine specimens from each material recieved no treatment.

The tested specimens were exaimined by optical microscope surface topography and then weighed by a sensitive weighing scale accurate up to $0.0001 \mathrm{gm}$.

\section{Optical interference microscope:}

Total samples were examined by Optical interference microscope before and after mechanical brushing test for surface topography evaluation using ZYGO Maxim-GP 200 profilometer, which is a surface optical profiler that measures the microstructure and topography of surfaces in three dimensions to analyze profiles and step height.

A monochromatic white light from a halogen lamp on an interference filter fall downwards and reflected back from the test object to the camera to form interference fringes. Using a computer and an advanced texture analysis software, all the surface related data can be obtained.

The instrument can measure step height up to $100 \mu \mathrm{m}$ with $0.75 \%$ accuracy.

\section{Group II,}

Twenty seven specimens 9 from each material were stored in acidic buffer for 168 hours then weighed.

\section{Preparation of solutions with different $\mathrm{pH}$ values}

Specimens of group II were stored in acidic buffer for168 hours (7 days).

A $200 \mathrm{ml}$ acidic buffer solution of $3 \mathrm{pH}$ were prepared (ABS) with a composition of (1.6 gm $\mathrm{NaCl}, 0.04$ gm KCl, 0.288 gm Na2HPO 4, 0.048 gm KH2PO4). The $\mathrm{pH}$ acidic buffer was adjusted using $\mathrm{HCl}$ (hydrochloric acid). ${ }^{12}$

The specimens were stored in $\mathrm{pH} 3$ buffer solutions for 7 days and preserved in an incubator at $37^{\circ} \mathrm{C}$ during the test duration before storage. Specimens were placed in a shaker at $55^{\circ} \mathrm{C}$ for two hours prior to placement at the incubator to accelerate the $\mathrm{pH}$ aging process.

After 7 days the specimens were dried and weighed

The data were collected and statistically analyzed.

\section{Group III,}

Twenty seven specimens 9 specimens from each material were subjected to mechanical brushing and examined by optical microscope (for quantity and quality of surface roughness).

\section{Mechanical brushing}

Tested specimens were subjected to mechanical brushing using custom made tooth brush abrasion machine, Dental Biomaterial Department Alexandria University, to accomplish brushing action as close as possible to that occurring in the oral cavity. This machine is equipped with a motor that produced a reciprocating motion on three hard nylon bristle tooth brush heads (oral B). The specimens were subjected to a total number of 50 000 cycles simulating an oral environment of 5 years. Brushing cycles and dentifrice ${ }^{19}$ of $25 \mathrm{ml}$ Colgate dentifrices in $15 \mathrm{ml}$ water were applied to the tuft of the tooth brushes and to the surfaces of the specimens. The specimens were held in the special copper mold which was attached to the base of the bath in which the slurry was placed. The experimental units were aligned so that the brushing head moved parallel to their surface. The tooth brushes were checked to insure direct contact with the surface of the specimens. Constant pressure of 350 grms was applied to the top of each brush to ensure equal loading between the brushes and the specimens.

A new brush was used every 2000 double strokes. The specimens were maintained in relative humidity at $37^{\circ} \mathrm{C}$ for 24 hours before the examination of surface roughness. ${ }^{19}$ 


\section{Surface Roughness Measurement.}

Surface roughness of the specimens were measured again after the brushing cycles for quantity and quality using optical interference microscope ZYGO Maxim-GP 200 profilometer, in which three point on the surface were examined before and after mechanical brushing

The results were recorded, tabulated, and statistically analyzed to compare between the changes in the surface before and after brushing.

The raw data were obtained from different tests and analyzed.

T test and One-way ANOVA were conducted to compare the effect of the acid buffer storage period and mechanical brushing on the weight loss and surface roughness repectively .

\section{RESULTS}

\section{Acidic buffer test Result}

\section{Statistical analysis:}

The Data were collected and entered into the personal computer. Statistical analysis was done using Statistical Package for Social Sciences (SPSS/ version 21.0) software.

Arthematic mean, standard deviation, and $\mathrm{t}-$ test was used for comparison between two groups. While for three groups ANOVA test was used for parametric data. The level of significant was 0.05 .

Twenty seven specimens nine from each tested material were used to measure weight loss before and after the storage in acidic buffer.

Mean values and standard deviations (SD) of the specimens were calculated for each group using t test. $\mathrm{T}$ tests were performed to compare the weight loss value at a baseline with those following the storage in acidic buffer for each material individually. Table (II) Figure (1)
The mean value of the weight of the Celtra Duo before the storage in acidic buffer was (0.719) and after the storage in acidic buffer was(0.711) which showed decrease in weight but without significant difference. This decrease in weight means that there was no progressive change before and after the storage in acidic buffer in the Celtra Duo specimens

The mean weight of Vita Enamic specimens before the storage in acidic buffer was (0.714) and after the storage in acidic buffer was $(0.703)$ which showed decrease in specimens weight but without significant difference. This non- significant difference in weight loss value revealed that there was no progressive change before and after the storage in acidic buffer in the Vita Enamic specimens.

The weight loss of Cerasmat specimens before storage in acidic buffer was $(0.482)$ and after storage was (0.470) which showed decrease in specimens weight but without significant difference.

This non significant difference in weight loss value found revealed that there was no progressive change before and after the storage in acidic buffer in the Cerasmat specimens.

Comparison between weight loss before and after acidic buffer storage in the three group using ANOVA analysis test showed that there was no significant difference between the three groups regarding weight loss (0.05). The weight loss of cerasmart group was higher than the other two groups.

\section{Results of the surface roughness test:}

Twenty seven specimens nine from each tested material were used to measure surface roughness before and after the mechanical tooth brushing. Table (III) Figure (2)

Mean values and standard deviation (SD) of the specimens were calculated for each group using $\mathrm{t}$ test. $\mathrm{T}$ tests were performed to compare the Ra value at a baseline with those following 50,000 
cycles for each material individually.

No significant difference was found between surface roughness value "Ra value" at the baseline before mechanical brushing and after 50,000 cycle for the Celtra Duo specimens $(0.624 \pm 0.237$ and $0.670 \pm 0.294)$. This means that the surface texture of the Celtra Duo did not show a progressive change in the surface topography by tooth brushing after 50,000 cycles.

Surface roughness of Vita Enamic specimens revealed that there was no significant difference between surface roughness value "Ra value" at the baseline and following 50,000 brushing cycles $(0.325 \pm 0.057$ and $0.336 \pm 0.066)$. This means that there is no change in the surface texture of the Vita Enamic specimens by tooth brushing after 50,000 cycles.

Surface roughness of Cerasmat specimens revealed that there was no significant difference between surface roughness value "Ra value" at the baseline and following 50,000 brushing cycles $(0.245 \pm 0.016$ and $0.285 \pm 0.012)$. This means that there is no change in the surface texture of the Cerasmat specimens by tooth brushing after 50,000 cycles.

ANOVA Test was applied to determin the difference in the mean values among the three groups. The results indicated that there was no significant difference among the tested groups following 50,000 brushing cycles, the Vita Enamic materials showed lower surface roughness mean value compared to surface roughness value of Celtra Duo and Cerasmart material .

\section{Surface Roughness results:}

Optical interference microscope describes roughness results by colored scale indicating elevations and depressions before and after mechanical abrasion in the following figures. Fig (3-8)

Images obtained by optical interference microscope showed that Vita Enamic was the lowest surface roughness, showing more color scale variations, followed by Celtra Duo and Cerasmart showed highest variations.

TABLE (II): Comparison between weight before and after treatment and weight loss in the three groups.

\begin{tabular}{|c|c|c|c|c|c|}
\hline \multirow[t]{2}{*}{ Tested Materials } & \multirow[b]{2}{*}{ Treatment } & \multirow{2}{*}{ Mean } & \multirow{2}{*}{ S.D. } & \multicolumn{2}{|c|}{ Paired Samples Test } \\
\hline & & & & $\mathbf{T}$ & P-value \\
\hline \multirow{2}{*}{ Vita Enamic } & Before & 0.719 & 0.021 & \multirow{2}{*}{0.91} & \multirow{2}{*}{ 0.122 N.S. } \\
\hline & After $168 \mathrm{hrs}$ & 0.711 & 0.022 & & \\
\hline \multirow{2}{*}{ Celtra Duo } & Before & 0.714 & 0.016 & \multirow{2}{*}{1.013} & \multirow{2}{*}{0.207 N.S. } \\
\hline & After $168 \mathrm{hrs}$ & 0.703 & 0.027 & & \\
\hline \multirow{2}{*}{ Cerasmart } & Before & 0.482 & 0.016 & \multirow{2}{*}{1.11} & \multirow{2}{*}{0.207 N.S. } \\
\hline & After $168 \mathrm{hrs}$ & 0.470 & 0.0098 & & \\
\hline \multirow{3}{*}{ Weight loss } & Vita Enamic & 0.008 & 0.0001 & \multirow{3}{*}{$\begin{array}{c}\text { ANOVA } \\
1.65\end{array}$} & \multirow{3}{*}{0.27 N.S. } \\
\hline & Celtra, Duo & 0.011 & 0.003 & & \\
\hline & Cerasmart & 0.012 & 0.004 & & \\
\hline
\end{tabular}


TABLE (IV): Comparison between roughness before and after treatment and difference in Roughness in the three groups.

\begin{tabular}{|c|c|c|c|c|c|}
\hline \multicolumn{2}{|l|}{ Tested Materials } & \multirow{2}{*}{ Mean } & \multirow{2}{*}{ S.D. } & \multicolumn{2}{|c|}{ Paired Samples Test } \\
\hline \multicolumn{2}{|r|}{ Treatment } & & & $\mathbf{T}$ & P-value \\
\hline \multirow{2}{*}{ Vita Enamic } & Before Mechnical Brushing & 0.325 & 0.057 & \multirow{2}{*}{1.07} & \multirow{2}{*}{0.102} \\
\hline & After Mechnical Brushing & 0.336 & 0.066 & & \\
\hline \multirow{2}{*}{ Celtra, Duo } & Before Mechnical Brushing & 0.624 & 0.237 & \multirow{2}{*}{1.42} & \multirow{2}{*}{0.098} \\
\hline & After Mechnical Brushing & 0.670 & 0.294 & & \\
\hline \multirow{2}{*}{ Cerasmart } & Before Mechnical Brushing & 0.245 & 0.016 & \multirow{2}{*}{0.89} & \multirow{2}{*}{0.45} \\
\hline & After Mechnical Brushing & 0.285 & 0.012 & & \\
\hline \multirow{3}{*}{$\begin{array}{l}\text { Difference in } \\
\text { Roughness }\end{array}$} & Vita Enamic & -0.011 & 0.003 & \multirow{3}{*}{$\begin{array}{c}\text { ANOVA } \\
2.51\end{array}$} & \multirow{3}{*}{0.068} \\
\hline & Celtra, Duo & -0.046 & 0.001 & & \\
\hline & Cerasmart & -0.048 & 0.002 & & \\
\hline
\end{tabular}

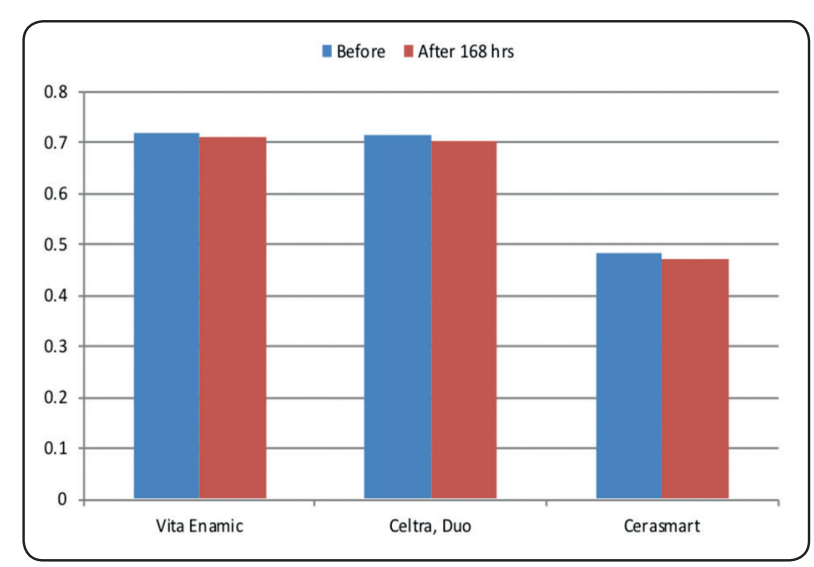

Fig. (1): Comparison between weight before and after treatment in the three groups.

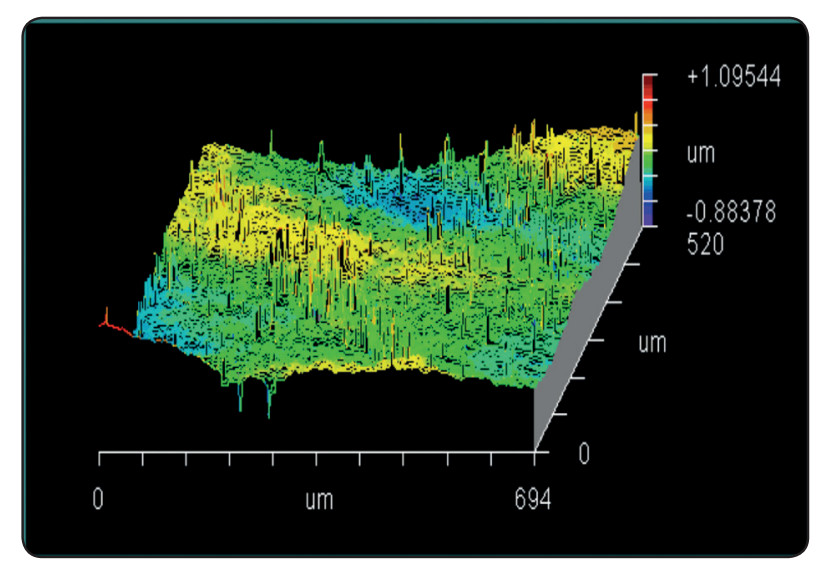

Fig. (3): Cerasmart specimens before machinal brushing

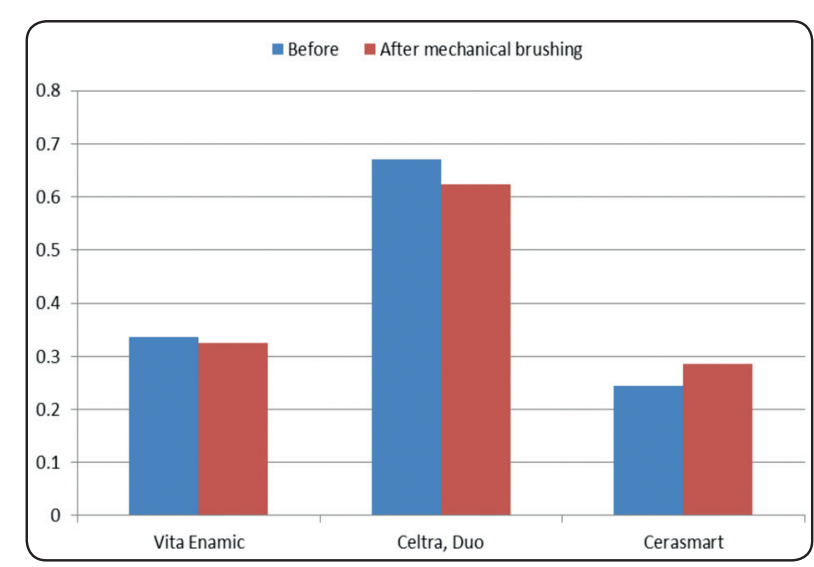

Fig. (2): Comparison between roughness before and after treatment and difference in roughness in the three groups.

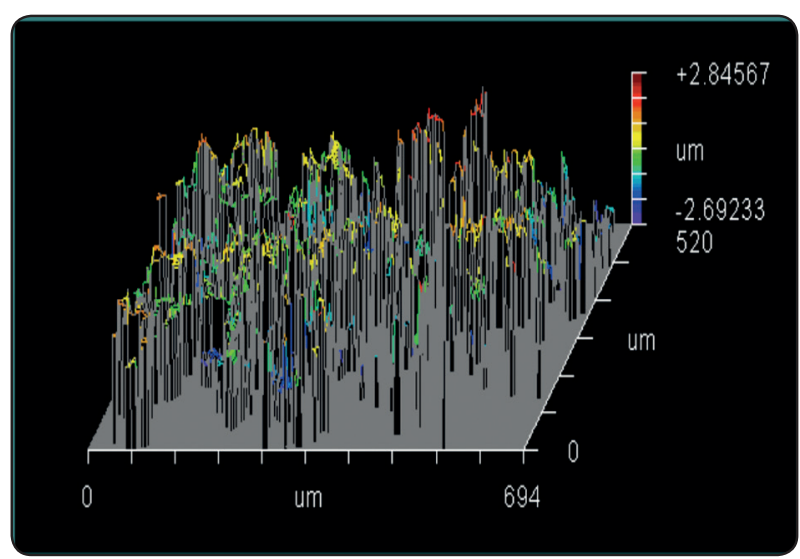

Fig. (4): Cerasmart specimens after mechanical brushing 


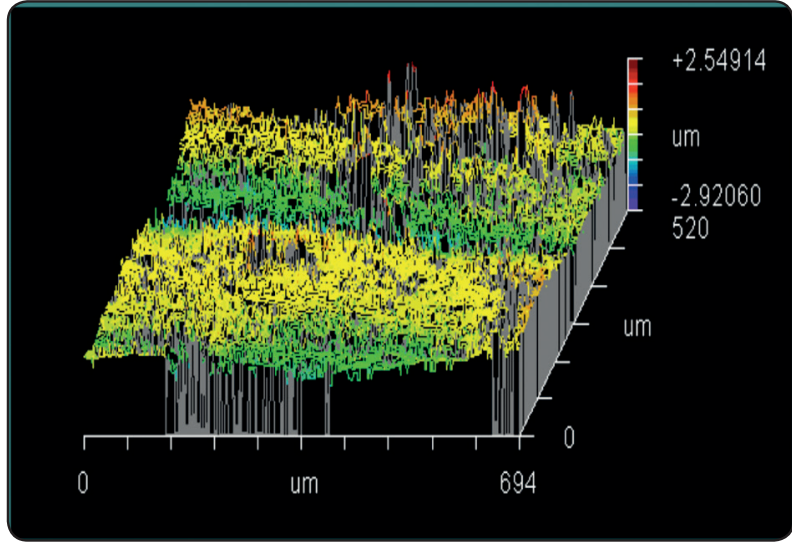

Fig. (5): Celtra Duo specimens before mechanical brushing

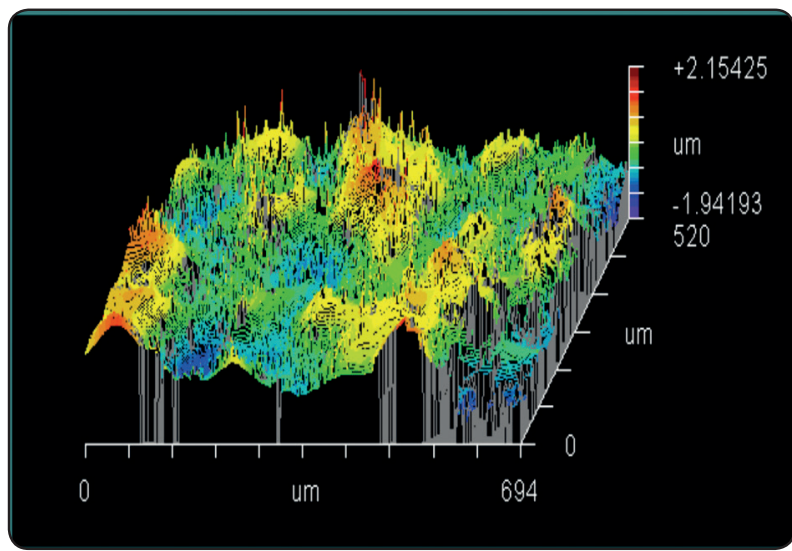

Fig. (7): Vita Enamic specimens before mechanical brushing

\section{DISCUSSION}

The results of this study compeletly support the hypotheses. After exposure to acidic buffer and mechnical tooth brushing there was no significant difference in weight loss and surface roughness among the tested materials.

The ceramics degradation as a result of exposure to acidic buffer give an idea about their behavior within the oral environment. Many factors affect the ceramics degradation as the presence of glassy matrix, size of the crystalline phase, and presence of oxides. ${ }^{20}$

Degradation caused by the storage in acidic buffer might be as a result of low $\mathrm{pH}$ of the acid in addition to its chelating effect on the tested materials

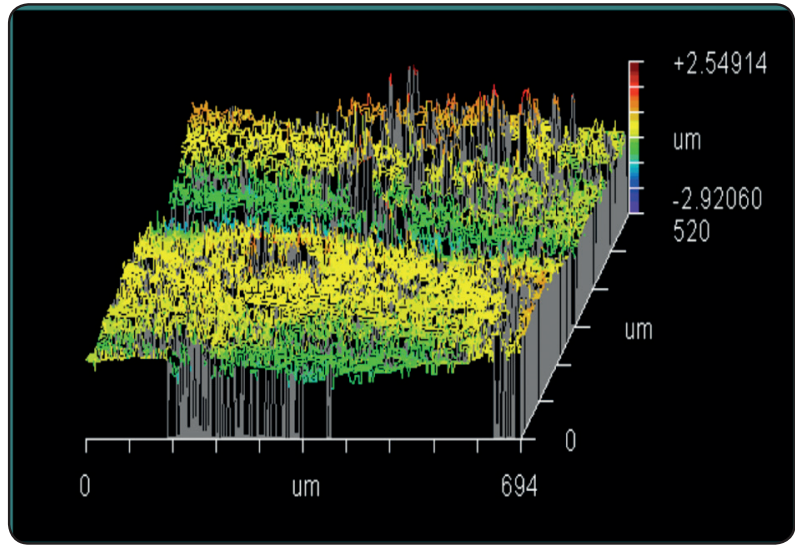

Fig. (6): Celtra Duo specimens after mechanical brushing

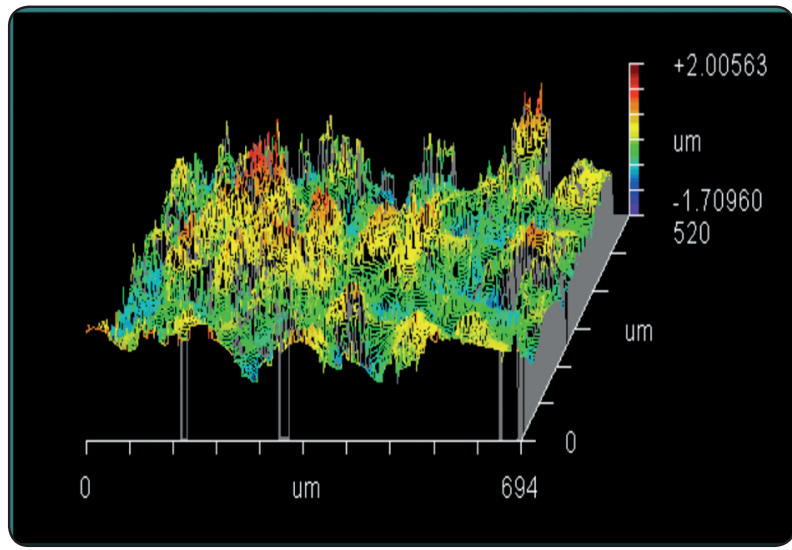

Fig. (8): Vita Enamic specimens after mechanical brushing

that cause leaching of alkaline ions and dissolution of the glass matrix

It is claimed that the lithium disilicate glass ceramics reinforced with $10 \%$ zirconia by weight have higher strength than the traditional lithium disilicate ceramics. ${ }^{21}$

Several studies confirm that the polymer infiltrated ceramic materials have improved mechanical properties due to its microstructure, that is composed of ceramic network that provides high resistance to wear in the same time the infiltrated polymer network that facilitates the resistance to fracture. $^{22}$

Composites have many advantages over ceramics like low abrasive effect, ease of milling, and easier 
intraoral repair due to their resin-based structure. ${ }^{23}$

The current study evaluated the effect of intraoral $\mathrm{pH}$ media, before and after storage in acidic buffer on the weight loss, and the effect of mechanical tooth-brushing for 50,000 cycles, on the surface roughness of zirconia-reinforced lithium silicate glass ceramics, hybrid ceramics and nano composite CAD/CAM blocks.

In this study all disc specimens were polished using ascending sequence of silicon carbide paper discs of 400, 600, 800,1000,1200 grit to obtian baseline reference point and to make sure they have the same surface roughness as a method of surface standardization. Specimens were cleaned using distilled water to protect the polymer content in the hybrid ceramic. Several studies showed that polishing by silicon carbide paper (SiC) made the tested specimens have an accepted baseline reference of surface roughness. ${ }^{24}$

The effects of acidic food are proved to be the main cause of apatite crystals dissolution. ${ }^{25}$ However, little information is known about their effect on ceramic restorations.

Acidic buffer solutions are preferred over acidic solutions as it is close to the oral environment composition because they contain ions like phosphate, chloride, potassium, and sodium that simulate the oral environment. ${ }^{26}$

After 168 hours the specimens were rinsed with distilled water, dried, and weighed to examine weight loss which revealed the acid effect.

Analysis of the results of this study, showed that the Cerasmart specimens had the highest weight loss after storage in acidic $\mathrm{pH}$ for 1 week and Vita Enamic specimens showed the lowest amount of weight loss without significant difference among the tested groups. The results were correlated to a study done by Harryparsad et al, ${ }^{27}$ who showed that glass ceramic materials are prone to weight loss due to acidic dissolution of filler particles. The dissolution of silica particles will result in weight loss ..$^{28,29}$
Kukiattrakoon B et $\mathrm{al}^{30}$ concluded that porcelain had leaching of ions after 168 hours of immersion in acidic agents. The more $\mathrm{pH}$ concentration, the more the degradation process compared with intraoral environment.

The Surface roughness $(\mathrm{Ra})$ parameter has a great value that provide an idea about the depth of the scratches present on a material's surface. Therefore, it is important to study the surface topography of the materials both quantitatively and qualitatively.

This study used the tooth brushing testing machine to give 50,000 strokes simulating the use of toothbrush for approximately 5years in addition, the Colgate dentifrice for daily tooth brushing.

The tested groups showed insignificant difference in surface roughness value between the tested groups with a higher roughness value after mechanical brushing in Cerasmart composite group, and lower roughness value after in Vita Enamic compared to zirconia reinforced lithium silicate glass ceramic. This may be due to the composition of Cerasmart composites which affect the toothbrush wear behaviour and consequently surface roughness..

Ghazal et al ${ }^{31}$ reported that the increase in surface roughness of the ceramic significantly increased the wear of the antagonistic human enamel and they recommended that ceramics must be highly polished with an average surface roughness not greater than $0.75 \mu \mathrm{m}$. Krid et al. ${ }^{32}$ reported that most of the composite resin CAD/CAM blocks has surface roughness comparable to ceramic blocks which coincide with the results of this study.

A smooth surface of restorative materials is an important parameter for patients. Jones et $\mathrm{al}^{33}$ reported that patients were able to distinguish a roughness value of $0.5 \mu \mathrm{m}$ clinically in addition to the essential role of surface roughness on the wear behavior of human enamel and opposing restorative materials. 
Several studies reported that Vita Enamic has lower hardness than glass ceramics in addition to a modulus of elasticty close to that of dentin ${ }^{34}$. Awada and Nathanson ${ }^{35}$ in their study concluded that the decrease in hardness of the materials may induce lower enamel wear to the antagonist . Lawson et $\mathrm{al}^{36}$ showed that the zirconia-reinforced lithium silicate material, Celtra Duo, is harder than Vita Enamic as a result induce higher rate of enamel wear. On the other hand Ludovichetti $\mathrm{F}^{37}$ et al in their study found that there was no relation between surface roughness and wear behavior of enamel.

The Ra values of the Vita Enamic and Celtra Duo specimens were not significantly different before and after the mechanical tooth brushing cycles. This might be related to the ceramic network composition that increase the materials hardness. This was in agreement with Kamonkhantikul K et $a{ }^{38}$ who found that there were no significant difference between Vita Enamic and Vitablocs after tooth-brushing cycles and explained their results by the strong ceramic network of these materials that might responsible for the behavior of the wear resistance of both materials .

Vita Enamic material is composed of infiltration of a ceramic network with a polymer. This microstructure results in a wear process compeletly different from other composite materials. The wear process of composite materials involves wear of the polymer matrix, followed by exposure of the fillers and its detachment from the matrix without fracture that results in surface roughness. ${ }^{39}$

Flury Si et al ${ }^{40}$ found that composite materials were more prone to degradation by artificial toothbrushing than Vita Enamic or feldspathic based ceramics which was in accordance with the result of this study.

Many studies investigated the effects of the mechanical tooth-brushing on the surface topography of resin restorations, and glass-based ceramic materials. Little information is available for lithium disilicate reinforced by zirconia crystals.
Yuan $\mathrm{J}$ et $\mathrm{al}^{41}$ reported that the surface roughness of lithium disilicate ceramic was significantly higher for longer simulated cycles (15 years) than 5 years.

Koizumi et $\mathrm{a}^{42}$ found that the Ra of the Cerasmart materials were higher than that of the ceramic block after toothbrush abrasion which was in agreement with the result of this study.

This study revealed that the increase in roughness of the composite materials over ceramics may be due to the instability of the polymer matrix, these changes are due to the absorption and diffusion of water to the resin matrix and between the inorganic filler resin interfaces in contrast to the zirconium reinforced ceramics and interpenetrated which showed no significant variation in the surface roughness due to the stability of these materials.

\section{CONCLUSIONS}

Within the limitations of the present study, there was no significant difference in surface roughness after 5 years simulated brushing and there was no significant difference in weight loss after 168 hours time storage in acidic buffer of the tested materials but the Cerasmart composite has the highest value of both weight loss and surface roughness.

\section{REFERENCES}

1. Rashid H. The effect of surface roughness on ceramics used in dentistry: A review of literature. European Journal of Dentistry2014; 84: 571-579.

2. Gemalmaz D, and Alkumru H. Marginal fit changes during porcelain firing cycles.J Prosthet Dent 1995;73:49-54.

3. Rashid H. The effect of surface roughness on ceramics used in dentistry: A review of literature. Eur J Dent. 2014;8:571.

4. Lange RT, Pfeiffer P. Clinical evaluation of ceramic inlays compared to composite restorations. Oper Dent 2009; $34: 263-72$

5. Elmaria A, Goldstein G, Vijayaraghavan T, Legeros RZ,Hittelman EL. An evaluation of wear when enamel isopposed by various ceramic materials and gold. J ProsthetDent 2006;96:345-53. 
6. Kukiattrakoon B, Junpoom P, Hengtrakool C. Vicker's microhardness and energy dispersive x-ray analysis offluorapatite-leucite and fluorapatite ceramics cyclically immersed in acidic agents. J Oral Sci 2009; 51:443-50.

7. Kukiattrakoon B, Junpoom $\mathrm{P}$, Hengtrakool C. Vicker'smicrohardness and energy dispersive x-ray analysis offluorapatite-leucite and fluorapatite ceramics cyclicallyimmersed in acidic agents. J Oral Sci 2009; 51:443-50.

8. Esquivel-Upshaw JF, Dieng FY, Clark AE, Neal D, AnusaviceKJ. Surface degradation of dental ceramics as a function ofenvironmental pH. J Dent Res 2013;92:467-71.

9. Judy Chia-Chun Yuan, Valentim Adelino Ricardo Barão, Alvin G. Wee, Maria F. Alfaro, Fatemeh S. Afshari, and Cortino Sukotjo. Effect of brushing and thermocycling on the shade and surface roughness of CAD-CAM ceramic restorations. J Prosthet Dent 2018;119:1000-6.

10. Goldstein G., Lerner T. The effectof tooth brushing on a hybrid composite resin. J Prosthet Dent 1991; 66: 498-500.

11. Esquivel-Upshaw JF, Dieng FY, Clark AE, Neal D, Anusavice KJ. Surface degradation of dental ceramics as a function ofenvironmental pH. J Dent Res 2013;92:467-71.

12. Salma M. Fathya, Michael V. Swain. In-vitro wear of natural tooth surface opposed with zirconia reinforced lithium silicate glass ceramic after accelerated ageing. Dent Mater 2018; 34:551-559.

13. Elsaka SE, Elnaghy AM. Mechanical properties of zirconia reinforced lithium silicate glass-ceramic. Dent Mater 2016;32:908-14.

14. Della Bona A, Corazza PH, Zhang Y. Characterization of a polymer infiltrated ceramic-network material. Dent Mater 2014;30:564-9.

15. Heintze SD, Forjanic M. Roughness of different dental materials before and after simulated toothbrushing in vitro. Oper Dent 2005;30:617-26.

16. Hahnel S, Henrich A, Bürgers R, Handel G, Rosentritt M. Investigation of mechanical properties of modern dental composites after artificial aging for one year. Oper Dent 2010;35:412-9.

17. Heintze SD., Forjanic M, Ohmiti K., Rousson V. Surface deterioration of dental materials after simulated toothbrushing in relation to brushing time and load. Dent Mater 2010; 2 6:306-319
18. Ferhan Egilmeza, Gulfem Erguna, Isil Cekic-Nagasa, Pekka K. Vallittub, Lippo V.J. Lassilac. Does artificial aging affect mechanical properties of CAD/CAM composite materials. J of prosthodontic research $2018 ; 62: 65-74$

19. Simon Flury, Elisabeth Diebold, med dent, Anne Peutzfeldt, odont, Pand Adrian Lussi. Effect of artificial toothbrushing and water storage on the surface roughness and micromechanical properties of tooth-colored CAD-CAM materials .J Prosthet Dent 2017;117:767-774.

20. Lawson NC, Bansal R, Burgess JO. Wear, strength, modulus and hardness of CAD/CAM restorative materials. Dent Mater 2016;32:275-83.

21. Milleding P, Haraldsson C, Karlsson S. Ion leaching from dental ceramics during static in vitro corrosion testing. $\mathrm{J}$ Biomed Mater Res 2002;61:541-50.

22. Elsaka SE, Elnaghy AM. Mechanical properties of zirconiareinforced lithium silicate glass-ceramic. Dent Mater 2016;32:908-14.

23. Okada K, Kameya T, Ishino H, Hayakawa T. A novel technique for preparing dental CAD/CAM composite resin blocks using the filler press and monomer infiltration method. Dent Mater J 2014;33:203-9.

24. El Zhawi H, Kaizer MR, Chughtai A, Moraes RR, Zhang Y. Polymer infiltrated ceramic network structures for resistance to fatigue fracture and wear. Dent Mater 2016;32:1352-61.

25. Li X, De Munck J, Van Landuyt K, Pedano M, Chen Z, VanMeerbeek B. How effectively do hydraulic calciumsilicatecements re-mineralize demineralized dentin. Dent Mater2017;33:434-45.

26. Takanashi E, Kishikawa R, Ikeda M, Inai N, Otsuki M,Foxton RM, Tagami J. Influence of abrasive particle size on surface properties of flowable composites. Dent Mater J 2008;27: 780-786.

27. Harryparsad A, Dullabh h, Sykes 1, Herbst D. The effects of hydrochloric acid on all-ceramic restorative materials: an in-vitro study. SADJ 2014; 69 : 106-111.

28. Nguyen JF, Migonney V, Ruse ND, Sadoun M. Resin composite blocks via high-pressure high-temperature polymerization. Dent Mater 2012;28:529-34.

29. Della Bona A, Anusavice KJ. Microstructure,composition and etching topography of dental ceramics. Int J Prosthodont. 2002;15:159-67. 
30. Boonlert Kukiattrakoon, Chanothai Hengtrakool, Ureporn Kedjarune-Leggat. Effect of Acidic Agents on Surface Roughness of Dental Ceramics. Dent Res J 2011; 8: 6-15.

31. Ghazal M, and Kern M. The influence of antagonistic surface roughness on the wear of human enamel and nanofilled composite resin artificial teeth. J Prosthet Dent 2009; 101: 342-349.

32. Krid Kamonkhantiku, Mansuang Arksornnukit, Sasipin Lauvahutanon and Hidekazu Takahashi.Toothbrushing alters the surface roughness and gloss of composite resin CAD/CAM blocks. Dental Materials Journal 2016; $35: 225-232$

33. Jones CS, Billington RW, Pearson GJ. The in vivo perception of roughness of restorations.Br Dent J 2004;196:4245. Quoted from Ghazal M, and Kern M. The influence of antagonistic surface roughness on the wear of human enamel and nanofilled composite resin artificial teeth. J Prosthet Dent 2009; 101: 342-349.

34. Chan YL, Ngan AHW, King NM. Nano-scale structure and mechanical properties of the human dentineeenamel junction. J Mech Behav Biomed Mater 2011;4:785-95.

35. Awada A, Nathanson D. Mechanical properties of resinceramic CAD/CAM restorative materials. J Prosthet Dent 2015;114:587-93.

36. Lawson NC, Bansal R, Burgess JO. Wear, strength, modulus and hardness of CAD/CAM restorative materials. Dent Mater 2016;32:e275-83.
37. Francesco Saverio Ludovichetti, Flávia Zardo Trindade, Arie Werner, Ing,Cornelis Johannes Kleverlaan, and Renata Garcia Fonseca. Wear resistance and abrasiveness of CAD-CAM monolithic materials. J Prosthet Dent 2018;120:318.e1-e8.

38. Kamonkhantikul K, Arksornnukit M, Takahashi H, Kanehira M, Finger WJ. Polishing and toothbrushing alters the surface roughness and gloss of composite resins. Dent Mater J 2014;33: 599-606.

39. Garza LA, Thompson G, Cho SH, Berzins DW. Effect of toothbrushing onshade and surface roughness of extrinsically stained pressable ceramics. J Prosthet Dent 2016;115:489-94.

40. Simon Flury, Elisabeth Diebold, Anne Peutzfeldt, and Adrian Lussi. Effect of artificial toothbrushing and water storage on the surface roughness and micromechanical properties of tooth-colored CAD-CAM materialsI. J Prosthet Dent 2017;117:767-774.

41. Judy Chia-Chun Yuan, Valentim Adelino Ricardo Barão, Alvin G. Wee, B Maria F. Alfaro,Fatemeh S. Afshari, and Cortino Sukotjo. Effect of brushing and thermocycling on the shade and surface roughness of CAD-CAM ceramic restorations. J Prosthet Dent 2018;119:1000-6.

42. Hiroyasu Koizumi, Osamu Saiki, Hiroshi Nogawa, Haruto Hiraba, Tomoyo Okazaki and Hideo Matsumura. Surface roughness and gloss of current $\mathrm{CAD} / \mathrm{CAM}$ resin composites before and after toothbrush abrasion. J Dent Mater 2015; 34: 881-887 